Original Research Article

\title{
Prescribing pattern and drug utilization study in inpatients of department of Orthopaedics in a rural teaching hospital of Ujjain, Madhya Pradesh, India
}

\author{
Ruchi Baghel $^{1}$, Sandeep K. Adwal ${ }^{1 *}$, Vivek Singh ${ }^{2}$, Ashutosh Chourishi ${ }^{3}$
}

\begin{abstract}
${ }^{1}$ Department of Pharmacology, ${ }^{2}$ Department of Orthopaedics, R.D. Gardi Medical College, Ujjain, Madhya Pradesh, India ${ }^{3}$ Department of Pharmacology, Govt. Medical College, Shivpuri, Pradesh Province, India
\end{abstract}

Received: 27 June 2018 Accepted: 26 July 2018

\section{*Correspondence to: Dr. Sandeep K. Adwal, Email: adwalsandeep@ yahoo.co.in}

Copyright: () the author(s), publisher and licensee Medip Academy. This is an openaccess article distributed under the terms of the Creative Commons Attribution NonCommercial License, which permits unrestricted noncommercial use, distribution, and reproduction in any medium, provided the original work is properly cited.

\begin{abstract}
Background: Drug utilization study can increase our understanding of how drugs are being used. This study was done to evaluate the current drug prescribing trend in management of indoor patient of orthopaedic department and to comment on rationality of the prescribed medicines.

Methods: This is a prospective observational study conducted for 12 months, in Chandrikaben Rashmikant Gardi Hospital, a 600 bedded tertiary care rural based, teaching hospital. Total 611 patients were included in this study.

Results: Total 5416 drugs were prescribed in 611 prescriptions. Average number of drugs per prescription was 8.86. Average duration of prescription was 10.7 days. Percentage of drugs prescribed by generic name was $28.8 \%$. Percentage of encounter with an Antibiotic prescribed was $60.23 \%$ i.e. out of 611 prescriptions antibiotics were prescribed in 368. Percentage of encounter with an Injection prescribed was $63 \%$ which means out of 611 prescriptions, injectables were prescribed in 385. Percentage of drugs prescribed from National Essential Medicine List was $52.63 \%$. Percentage of drugs prescribed from WHO model List was $32.46 \%$. Diclofenac $(14.25 \%)$ was most commonly prescribed drug. Incidence of polypharmacy was quite high in context of Analgesics. Almost $40 \%$ of prescriptions had 2 drugs. Orally prescribed Analgesics were 62.6\%, Injectables $34.38 \%$ and Topical $3.02 \%$.

Conclusions: This study reveals that the pattern of prescription in terms of rationality is poor. Special attention needs to be given to the irrational prescribing in terms of polypharmacy and long duration. Continuing medical education regarding appropriate use of drugs, knowledge of adverse effects and standard prescription guidelines will play pivotal role in rational prescription of drugs.
\end{abstract}

Keywords: Drug utilization, Prescribing pattern, Rational use

\section{INTRODUCTION}

The principal aim of drug utilization research is to facilitate the rational use of drugs in populations. For individual patient, the rational use of a drug implies the prescription of a well-documented drug at an optimal dose, together with the correct information, at an affordable price. Without knowledge of how drugs are being prescribed and used, it is difficult to initiate a discussion on rational drug use or to suggest measures to improve prescribing habits. Information on the past performance of prescribers is the linchpin of any auditing system. Drug utilization research in itself does not necessarily provide answers, but it contributes to rational drug use in important ways. Drug utilization research can increase our understanding of how drugs are being used as follows: ${ }^{1}$

- $\quad$ It can be used to estimate the numbers of patients exposed to specified drugs within a given time period. Such estimates may either refer to all drug 
users, regardless of when they started to use the drug (prevalence) or focus on patients who started to use the drug within the selected period (incidence).

- It can describe the extent of use at a certain moment and/or in a certain area (e.g. in a country, region, community or hospital). Such descriptions are most meaningful when they form part of a continuous evaluation system, i.e. when the patterns are followed over time and trends in drug use can be discerned.

- Researchers can estimate (e.g. on the basis of epidemiological data on a disease) to what extent drugs are properly used, overused or underused.

- It can determine the pattern or profile of drug use and the extent to which alternative drugs are being used to treat particular conditions.

- It can be used to compare the observed patterns of drug use for the treatment of a certain disease with current recommendations or guidelines.

- It can be used in the application of quality indicators to patterns of drug utilization.

Studies on the utilization of drugs in the orthopaedics department are lacking in hospitals in India. Such studies are necessary to obtain baseline data on drug use and create a database for comparison with future studies. Hence, to give continuation to the effort of promoting Rational Use of Drugs (RUD) we have planned the present study.

This study is aimed at assessing the drug prescribing trends in inpatients of orthopaedics department and recommend changes to improve prescribing pattern, if required.

\section{Objectives}

- To study the current drug prescribing trend in management of indoor patient of orthopaedic department.

- To comment on rationality of the prescribed medicines.

\section{METHODS}

A prospective observational study was conducted from in Chandrikaben Rashmikant Gardi Hospital, a 600 bedded tertiary care rural based, teaching hospital attached to Ruxmaniben Deepchand Gardi Medical College, Ujjain, Madhya Pradesh.

The protocol was prepared and presented to Human Research Ethics Committee of the institute and approved by the same.

\section{Study site}

The study was conducted in Department of Pharmacology, R.D. Gardi Medical College in collaboration with Department of Orthopaedics, Chandrikaben Roopchand Gardi Hospital (C.R.G.H), Ujjain.

\section{Study population}

Patients admitted to orthopaedics wards during the study period.

Data was collected from Case files of Inpatients. Total 611 patients were included in this study. Patients who were admitted to orthopaedics ward, C.R. Gardi Hospital were included in this study.

\section{Inclusion criteria}

Patients of all ages and both sexes were included.

\section{Collection of data}

The study was conducted for indoor patients. Relevant data of all 611 patients was collected from wards. Each patient included in the study was followed up every day till patient was discharged from the ward and their case files were reviewed for gathering necessary information as per the Data Collection form.

\section{RESULTS}

There were more male participants $73.16 \% \quad(n=447)$ compared to the female group $26.84 \%(n=164)$. More patients were from the age group $>60$ years $25.70 \%$ (i.e. 104 males and 53 females). There were $23.08 \%$ patients from age group 21-30 years and the least from the age group <20 years $11.62 \%$ (i.e. 60 male and 11 female patients). A total of 5416 drugs were prescribed. A brief description of the demographic data is presented.

\section{Demographic data}

Table 1 shows the frequency distribution of the demographic data with respect to gender and age group of total patients observed during study period. (Table 1)

Table 1: Age and sex wise distribution of total patient observed.

\begin{tabular}{|lllll|}
\hline Age group & Male & Female & Total & Percentage \\
\hline$<20$ years & 60 & 11 & 71 & $11.62 \%$ \\
\hline 21-30 years & 121 & 20 & 141 & $23.08 \%$ \\
\hline 31-40 years & 63 & 16 & 79 & $12.92 \%$ \\
\hline 41-50 years & 58 & 29 & 87 & $14.24 \%$ \\
\hline 51-60 years & 41 & 35 & 76 & $12.44 \%$ \\
\hline$>60$ years & 104 & 53 & 157 & $25.70 \%$ \\
\hline $\begin{array}{l}\text { Total } \\
\text { (Percentage) }\end{array}$ & 447 & 164 & 611 & $100 \%$ \\
\hline
\end{tabular}

There were more male $73.16 \%(n=447)$ compared to the female group $26.84 \%(n=164)$. More patients were from the age group $>60$ years $25.70 \%$ (i.e. 104 males and 53 females). There were $23.08 \%$ patients from age group 21 30 years and the least from the age group <20 years $11.62 \%$ (i.e. 60 male and 11 female patients). 
Table 2: Various diagnosis for which patients were admitted.

\begin{tabular}{|ll|}
\hline Diseases & Percentage \\
\hline Fracture & $58.43(\mathrm{n}=357)$ \\
\hline PIVD & $15.87(\mathrm{n}=97)$ \\
\hline Dislocation & $5.25(\mathrm{n}=32)$ \\
\hline Pott's Spine & $5.89(\mathrm{n}=36)$ \\
\hline Rheumatoid Arthritis & $4.58(\mathrm{n}=28)$ \\
\hline Osteoarthritis & $1.96(\mathrm{n}=12)$ \\
\hline Others & $8.02(\mathrm{n}=49)$ \\
\hline
\end{tabular}

Patients were most commonly admitted due to fractures in various body parts $(58.43 \%)$. Next common cause was PIVD which constituted $15.87 \%$ of patients.

\section{WHO prescribing indicators}

Data of all the 611 patients was collected and analysed for the Prescribing Indicators. Total 5416 drugs were prescribed in 611 prescriptions. Average number of drugs per prescription was 8.86. Average duration of prescription was 10.7 days. Percentage of drugs prescribed by generic name was $28.8 \%$. Percentage of encounter with an Antibiotic prescribed was $60.23 \%$ i.e. out of 611 prescriptions antibiotics were prescribed in 368 . Percentage of encounter with an Injection prescribed was $63 \%$ which means out of 611 prescriptions, injectables were prescribed in 385 . Percentage of drugs prescribed from National Essential Medicine List was 52.63\%. Percentage of drugs prescribed from WHO model List was $32.46 \%$.

Table 3: Prescribing indicators.

\begin{tabular}{|ll|}
\hline Prescribing indicators & \\
\hline Average numbers of drugs per encounter & 8.86 \\
\hline $\begin{array}{l}\text { Percentage of drugs prescribed by generic } \\
\text { name }\end{array}$ & $28.8 \%$ \\
\hline $\begin{array}{l}\text { Percentage of encounter with an Antibiotic } \\
\text { prescribed. }\end{array}$ & $60.23 \%$ \\
\hline $\begin{array}{l}\text { Percentage of encounter with an Injection } \\
\text { prescribed }\end{array}$ & $63 \%$ \\
\hline $\begin{array}{l}\text { Percentage of drugs prescribed from } \\
\text { Medicine List }\end{array}$ & $52.63 \%$ \\
\hline $\begin{array}{l}\text { Percentage of drugs prescribed from WHO } \\
\text { model List }\end{array}$ & $32.46 \%$ \\
\hline
\end{tabular}

Figure 1 shows various drugs comprising DU $90 \%$ segment. Diclofenac (14.25\%) was most commonly prescribed drug followed by Vit. B1+B2+Niacinamide (13.1\%), Calcium+D3+B12 (11.5\%), Famotidine (11.3\%), Ranitidine $(7.95 \%)$ and Amikacin $(4.4 \%)$.

\section{Analysis of antibiotic use}

Total number of antibiotics prescribed were 852 . Antibiotics were prescribed in 368 patients. Out of which 277 patients $(75.3 \%)$ of them were prescribed two antibiotics. Four antibiotics in 69 patients $(18.7 \%)$ have been prescribed and single antibiotic in 22 patients $(6.0 \%)$. Average number of antibiotic per patient was 2.3 and average duration of antibiotic prescription is 7.8 days.

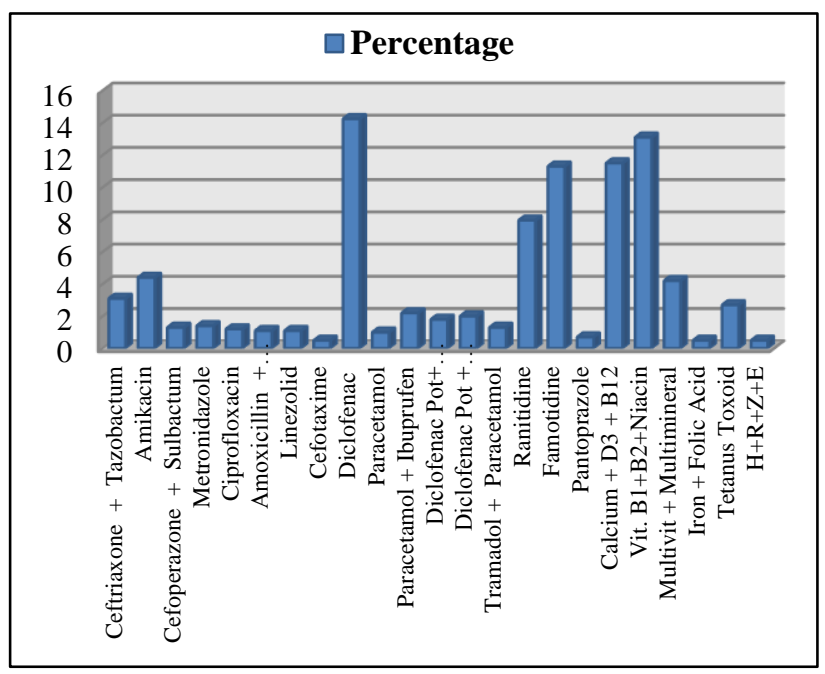

Figure 1: Drugs constituting DU90\% segment.

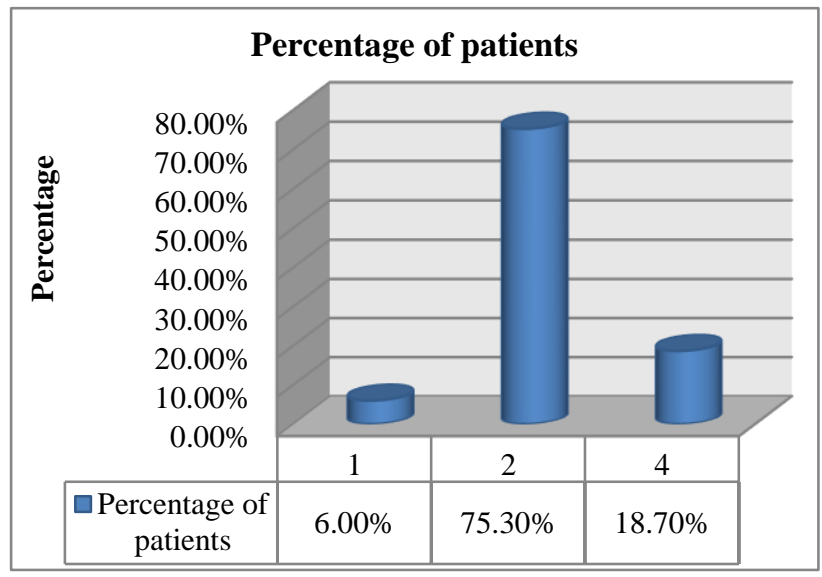

Figure 2: Number of antibiotics prescribed per encounter.

\section{Analysis of analgesic use}

Total number of Analgesics prescribed were 1368 which is $25.25 \%$ of total drugs. Average number of analgesics per prescription was 2.24 drugs per prescription.

Incidence of polypharmacy was quite high in context of Analgesics. Almost $40 \%$ of prescriptions had 2 drugs, $28 \%$ had 3 drugs and $8 \%$ had $>3$ drugs prescribed. Orally prescribed Analgesics were 62.6\%, Injectables $34.38 \%$ and Topical $3.02 \%$. Analgesics prescribed as FDC were $41.8 \%$. Prescriptions with two or more oral preparations were $35.68 \%$.

Gastro protective Agents were coprescribed in all instances to reduce or prevent the gastrointestinal irritation caused by NSAIDs. 
Table 4: Patterns of use of NSAIDs.

\begin{tabular}{|ll|}
\hline Category & $\begin{array}{l}\text { Number of } \\
\text { patients/ drugs } \\
\text { (Percentage) }\end{array}$ \\
\hline Incidence of polypharmacy $(\mathrm{n}=611)$ & $146(24 \%)$ \\
\hline One drug & $244(40 \%)$ \\
\hline Two drugs & $171(28 \%)$ \\
\hline Three drugs & $50(8 \%)$ \\
\hline$>$ Three drugs & $856(62.60 \%)$ \\
\hline Route of administration $(\mathrm{n}=1368)$ & $470(34.38 \%)$ \\
\hline Oral & $41(03.02 \%)$ \\
\hline Injection & $573(41.8 \%)$ \\
\hline Topical & $218(35.68 \%)$ \\
\hline $\begin{array}{l}\text { Percentage of Fixed dose } \\
\text { combinations (n=1368) }\end{array}$ & $100 \%$ \\
\hline $\begin{array}{l}\text { Percentage prescription with two or } \\
\text { more oral preparation }(\mathrm{n}=611)\end{array}$ & \\
\hline $\begin{array}{l}\text { Co prescribed with Gastro } \\
\text { protective agent (n=611) }\end{array}$ & \\
\hline
\end{tabular}

\section{DISCUSSION}

This is a prospective observational study conducted for 12 months, in Department of Orthopaedics, Chandrikaben Rashmikant Gardi Hospital, Ujjain, M.P. A total of 611 prescriptions were observed during the study period. A total of 5416 drugs were prescribed.

It was observed that majority of patients were in the age group of $>60 \mathrm{yrs} 25.70 \%$ (104 males and 53 females) followed by $23.08 \%$ patients from age group 21-30 years. A greater proportion of older persons have been also seen in patients in previous studies done in northern India. ${ }^{2}$

A possible reason could be the high proportion of old people develop age related bone changes which make them prone to fractures after trivial trauma. The next peak in age group of 21-30 years may be because this age group is more active and communicating therefore there are more chances for them to meet accidents.

Sex wise distribution of patients shows that male patients (447 out of 611) were found more than females (164) in this study. Male dominance was also found in the studies done by Gupta et al. ${ }^{2}$ This may be due to male dominance in society, as they are involved in outdoor activities and are earning members of the family, thus they are more exposed to trauma.

The most common diagnosis in our study, for which patients were admitted was Fracture of different parts of body. The commonest indications were low back ache and spondylosis in study done in Nepal. ${ }^{3}$ This may be because only out patients were included in their study.

The average number of drugs per prescription is an important parameter while doing a prescription audit. Average number of drugs per prescription was 8.86 . The mean number of drugs was higher than that reported in a previous study. ${ }^{4}$ A hospital based study in India had reported a mean number of two drugs. ${ }^{5}$ The mean number of drugs was more than two in other studies reported in the literature. ${ }^{2,6}$

Low $(28.8 \%)$ generic prescription of the drugs, especially at the tertiary level health facility could reflect the dominating influence of pharmaceutical companies. Our findings regarding generic prescribing are contrary to those of several studies carried out in other countries, while being similar to that of various studies carried out in India and the neighboring countries. ${ }^{7-11,13-18}$ Generic prescribing is to be encouraged as it works out to be cheaper for the patient and the possibility of drug errors is reduced.

Antibiotics were prescribed in $60.23 \%$ of encounters respectively. In a previous audit of prescriptions, antibiotics were prescribed in $47.8 \%$ of encounters. ${ }^{19}$ In Nigeria, antibiotics were prescribed in $50.3 \%$ of Encounters. ${ }^{20}$ The use of injections (63\% of encounters) in our study was very high compared to that observed by Rehan et al. ${ }^{21}$ But due to different patient populations the values are not comparable. The higher number of encounters with an antibiotic or injection prescribed is a warning sign and has to be discouraged. Out of total 5416 drugs, $52.63 \%$ of drugs were prescribed from the National Essential Medicine List. In a previous study at primary healthcare facilities in the Kaski district, the percentage of drugs prescribed from the Essential drug list varied from $70.9 \%$ to $74 \% .^{22}$

The low rate of prescribing of essential drugs is a matter of concern. Excessive use of multivitamin and combination preparations may be one of the factors responsible. It must be noted though that Essential drugs are primarily meant for primary healthcare systems while we studied drug utilization in a tertiary care hospital. Prescribing from WHO List was even lower (32.46\%). The extensive use of the Diclofenac, which is not on the WHO list, may be contributory factor.

DU $90 \%$ has been proposed as a single method for assessing the general quality of drug prescribing. It provides pertinent information on drug usage in patients. In the present study, Diclofenac is the major component of DU90\% segment followed by multivitamins. Out of different Drugs prescribed in present study, Analgesics, Antibiotics, Gastroprotective agents and nutritional supplements are the major drug categories falling in DU $90 \%$.

Average Antibiotic prescribed per patient was 2.3 and average duration was 7.8 days. However, in the present study, the low rate of antibiotic prescription does not indicate that the prescription pattern is better than in other countries, as no clinical determinants were documented in any prescription as criteria for justifying prescribing an antibiotic. It is worth noting that both under- and over- 
prescribing of antibiotics pose important problems in clinical practice. Multiple drug prescription (polypharmacy) increases both the risk of drug-drug interactions and the incidence of adverse drug reactions, and it may also reduce compliance. In this study at least two antibiotics were prescribed in $75.3 \%$ of prescriptions which is substantially more than reported in most Western countries.

Prevalence of Analgesics (NSAIDs) was $25.25 \%$ which is same when compared to various other studies done in urban setup, which has showed varied Analgesics (NSAIDs) prevalence pattern. In St. John's Medical College and Hospital Bangalore, frequency of Analgesics (NSAIDs) prescription was $24.52 \% .^{23}$ Similarly, study done in Dubai showed $23.4 \%$ of Analgesics (NSAIDs) prescription prevalence. ${ }^{24}$ However, study done in Nepal showed very less Analgesics prescription prevalence $(13.1 \%){ }^{25}$

Polypharmacy was seen with Analgesics also. About 40\% of prescriptions had 2 Analgesics prescribed and $28 \%$ with 3 Analgesics prescribed, this may lead to increase in adverse drug effects.

In this present study average number of Analgesics per prescription was 2.24 , which is less compared to studies conducted in Uttaranchal and Chandigarh, where Analgesic drug per prescription were 2.6 and 3 respectively. ${ }^{2,26}$

\section{CONCLUSION}

This study reveals that the pattern of prescription in terms of rationality is poor.

There is an urgent need to develop standards of drug prescription and develop ways and means to ensure that they are adhered to. Special attention needs to be given to the irrational prescribing in terms of polypharmacy and long duration. This could be done by making it mandatory for the prescribers to attend regular continuing medical education (CME), so as to update their knowledge. Continuing medical education regarding appropriate use of drugs knowledge of its potential adverse effects and standard prescription guidelines will play pivotal role in rational prescription of drugs.

A check on the influence of pharmaceutical companies needs to be maintained in health institutions, to minimize their influence on the drug prescription. All these measures would go a long way in providing optimal, low cost, and effective medicines to the patients.

\section{Funding: No funding sources} Conflict of interest: None declared

Ethical approval: The study was approved by the Institutional Ethics Committee

\section{REFERENCES}

1. Birkett D, Smet PD, Adjei DO, Trolin I, Bergman U, Strom H, Harbo BT and Ronning M. Introduction to Drug Utilization Research. WHO; 2003:6-9.

2. Gupta M, Malhotra S, Jain S, Aggarwal A, Pandhi P. Pattern of prescription of non-steroidal antiinflammatory drugs in orthopaedic outpatient clinic of a north Indian tertiary care hospital. 2005;37(6):404-5.

3. Prescribing patterns in the orthopaedics outpatient department in a teaching hospital in Pokhara, western Nepal. Shankar PR, Pai R, Dubey AK, Upadhyay DK. Kathmandu University Med J. 2007;5(1,17):16-21.

4. Sarkar C, Das B. Prescribing trends in a teaching hospital in western Nepal. JNGMC. 2002;2:4-7.

5. Hede SS, Diniz RS, Agshikar NV, Dhume VG.Pattern of prescribed and OTC drugs in North Goa. Indian J Pharmacol. 1987;19:145-8.

6. Rishi RK, Sangeeta S, Surendra K, Tailang M. Prescription audit: experience in Garhwal (Uttaranchal), India. Trop Doct. 2003;33:76-9.

7. Guyon AB, Barman A, Ahmed JU, Ahmed AU, Alam MS. A baseline survey at the primary health care level in Bangladesh. Bull World Health Organ. 1994;72:265-71. [PMC free article] [PubMed]

8. Massele AY, Mwaluko GM. A study of prescribing patterns at different health facilities in Dar es Salaam, Tanzania. East Afr Med J. 1994;71:314-6. [PubMed]

9. Bosu WK, Ofori-Adjei D. An audit of prescribing practices in health care facilities of the Wassa West district of Ghana. West Afr J Med. 2000;19:298-303. [PubMed]

10. Moghadamnia AA, Mirbolooki MR, Aghili MB. General practitioner prescribing patterns in Babol city, Islamic Republic of Iran. East Mediterr Health J. 2002;8:550-5. [PubMed]

11. Mallet HP, Njikam A, Scouflaire SM. Evaluation of prescription practices and of the rational use of medicines in Niger. Sante. 2001;11:185-93. [PubMed]

12. Bapna JS, Tekur U, Gitanjali B, Shashindran $\mathrm{CH}$, Pradhan SC, Thulasimani M, et al. Drug utilization at primary health care level in southern India. Eur J Clin Pharmacol. 1992;43:413-5. [PubMed]

13. Kshirsagar MJ, Langade D, Patil S, Patki PS. Prescribing patterns among medical practitioners in Pune, India. Bull World Health Organ. 1998;76:2715. [PMC free article] [PubMed]

14. Hazra A, Tripathi SK, Alam MS. Prescribing and dispensing activities at the health facilities of a nongovernmental organization. Natl Med J India. 2000;13:177-82. [PubMed]

15. Ravi Shankar P, Partha P, Nagesh S. Prescribing patterns in medical outpatients. Int $\mathrm{J}$ Clin Pract. 2002;56:549-51. [PubMed]

16. Shankar R, Kumar P, Rana M, Dubey A, Shenoy N. A comparative study of drug utilisation at different levels of the primary healthcare system in Kaski district, Western Nepal. N Z Med J. 2003;116:U602.[PubMed] 
17. Nwolisa CE, Erinaugha EU, Ofoleta SI. Prescribing practices of doctors attending to under fives in a children's outpatient clinic in Owerri, Nigeria. J Trop Pediatr. 2006;52:197-200. [PubMed]

18. Dawadi S, Rao BS, Khan GM. Kathmandu University Journal of Science, Engineering and Technology. Pattern of antimicrobial prescription and its cost analysis in respiratory tract infection; 2005:1.

19. Shankar PR, Partha P, Nagesh S. Prescribing patterns in medical outpatients. Int J Clin Pract. 2002;56:54951. [PubMed]

20. Chukwuani CM, Onifade M, Sumonu K. Survey of drug use practices and antibiotic prescribing pattern at a general hospital in Nigeria. Pharm World Sci. 2002;24:188-95. [PubMed]

21. Rehan HS, Lal P. Drug prescribing pattern of interns at a government healthcare centre in northern India. Trop Doct. 2002;32:4-7. [PubMed]

22. Shankar R, Kumar P, Rana M, Dubey A, Shenoy N. A comparative study of drug utilization at different levels of the primary health care system in Kaski district, Western Nepal. N Z Med J. 2003:116. [PubMed]

23. Srishyla MV, Krishnamurthy M, Naga Rani MA, Clare M, Andrade C, Venkataraman BV. Prescription audit in an Indian Hospital setting using the DDD (Defined Daily Dose) concept. Indian J Pharmacol 1994;26:23-8.

24. Sharif SI, Al-Shaqra M, Hajjar H, Shamout A, Wess L. Patterns of drug prescribing in a Hospital in Dubai, United Arab Emirates. Libyan J Med, AOP. 2005;070928:10-2.

25. Rehana HR, Nagarani MA, Rehan M. A study on the drug prescribing pattern and use of antimicrobial agents at tertiary careteaching hospital in eastern Nepal. Indian J Pharmacol. 1998;30:175-80.

26. Sharma T, Dutta S, Dhasmana DC. Prescription pattern of NSAIDs in Orthopaedic OPD of a tertiary care teaching Hospital in Uttaranchal. JK Science. July-sep 2006;8(3):160-2.

Cite this article as: Baghel R, Adwal SK, Singh V, Chourishi A. Prescribing pattern and drug utilization study in inpatients of department of Orthopaedics in a rural teaching hospital of Ujjain, Madhya Pradesh, India. Int J Basic Clin Pharmacol 2018;7:1763-9. 


\section{ANNEXURE}

\section{RUXMANIBEN DEEPCHAND GARDI MEDICAL COLLEGE}

Agar Road, Surasa, Ujjain (M.P.)

Prescribing pattern and Drug Utilization Study in inpatients of Dept of Orthopaedics in a Rural Teaching Hospital of Ujjain (M.P.)

\section{DATA COLLECTION FORM}

Hospital no. Date: Ward:

Initials: Age/Sex: Address:

Tel no.

Present illness \& Diagnosis:

Past history of any chronic disease \& treatment:

Date of surgery:

PRESENT TREATMENT:

PRE-OPERATIVE:

\begin{tabular}{|l|l|l|l|l|}
\hline S N & DRUG & (DOSE, ROA, FREQUENCY) & START DAY & END DAY \\
\hline & & & & \\
\hline
\end{tabular}

POST - OPERATIVE:

\begin{tabular}{|l|l|l|l|l|}
\hline S N & DRUG & (DOSE, ROA, FREQUENCY) & START DAY & END DAY \\
\hline & & & & \\
\hline
\end{tabular}

\section{NON-SURGICAL CASES:}

Present treatment:

\begin{tabular}{|l|l|l|l|l|}
\hline S N & DRUG & (DOSE, ROA, FREQUENCY) & START DAY & END DAY \\
\hline & & & & \\
\hline
\end{tabular}

Laboratory tests: 